The Journal of

Thoracic and

Cardiovascular

Surgery

\title{
Information for Authors
}

\section{Electronic manuscript submission is mandatory at http://jtcvs.editorialmanager.com}

\section{Editorial Office}

Electronic Submissions (mandatory): http://jtcvs.editorialmanager.com E-mail: jtcvs@drexel.edu (general correspondence)

Please address all non-Internet correspondence to:

Andrew S. Wechsler, MD, Editor

The Journal of Thoracic and Cardiovascular Surgery

Drexel University College of Medicine

245 N. 15th Street, Room 6415 NCB

Philadelphia, PA 19102-1192

Telephone: 215-762-1854

Fax: 215-762-3866

\section{General Information}

The Editors of The Journal of Thoracic and Cardiovascular Surgery aim to promote excellence in the discipline and educate those practicing and interested in our specialty. To this end, the Journal accepts submissions in the form of original articles, brief communications, clinical-pathological conferences, and letters to the Editor on topics pertaining to the most recent developments in cardiothoracic transplantation, general thoracic surgery, surgery for acquired and congenital cardiovascular disease, and technical and physiologic issues as they relate to the specialty. The Journal commits to rigorous peer review, freedom from commercial influence, and promotion of the highest ethical and scientific standards in our specialty.

\section{Editorial Policies}

Review: Three or more referees review each article. Acceptance is based on significance, originality, and validity of the material presented. If the article is accepted for publication, editorial revisions may be made to aid clarity and understanding without altering the meaning. Authors are given the opportunity to name a reviewer whom they believe is expert and impartial in their area of interest.

Guidelines for Reviewers: Because more papers are submitted to the Journal than can be published, only the very best papers should be recommended for publication. Accordingly, a manuscript should be evaluated not only with respect to its scientific competence and accuracy, but also its relative importance in the field of thoracic and cardiovascular surgery and for its probable interest to our readership. Among the issues to consider are:
- What is the importance of the research question or subject field study?

- Are the methods and experimental techniques adequate?

- Do the results seem to be reliable and presented clearly?

- Is the discussion relevant?

- Are the conclusions reasonable?

- Are the illustrations and references appropriate and necessary?

- Is the abstract informative and written in a style that will make it intelligible to readers who do not work in the specific area addressed by the abstract?

- Is the writing clear and the organization of the paper sound?

- What is the originality of the work?

If you recommend that a paper be shortened, you should indicate on the form "Comments to Authors" in which places it could be abbreviated and which figures or tables could be omitted. Please remember that it is the job of the copy editor to identify typographical and syntactic errors. Please focus your "Comments to Authors" on queries and constructive criticism. Do not put statements in the "Comments to Authors" form regarding the acceptability of the paper. If the editorial office or the other reviewers decide to reject the paper, such statements could be problematic.

Scientific Responsibility: Only those individuals who made direct contributions to the intellectual content of the paper may be listed as authors. Persons designated as authors should meet all of the following criteria:

1. Conceived and planned the work that led to the paper or interpreted the evidence presented, or both.

2. Wrote the paper, or reviewed successive versions and took part in the revision process.

3. Approved the final version.

The authors should describe the role of the study's sponsors in the following areas:

1. Designing the study

2. Collecting, analyzing, and interpreting the data

3. Writing the report

4. Making the decision to submit for publication

The JTCVS editorial staff will not consider for publication a report in which the researcher did not have full access to the data, the ability to analyze them independently from the sponsor, and sole authority to make the final decision regarding publication. The Editor may, if he deems it necessary, require a copy for verification of its content.

After a manuscript is accepted for publication, no author can be removed from the author list without the written permission of that author. 
Conflict of Interest: When the proposed publication concerns any commercial product, either directly or indirectly, the author must include in the cover letter a statement (1) indicating that he or she has no financial or other interest in the product or distributor of the product or (2) explaining the nature of any relation between himself or herself and the manufacturer or distributor of the product. Other kinds of associations, such as consultancies, stock ownership, or other equity interests or patent-licensing arrangements, also must be disclosed. If, in the Editor's judgment, the information disclosed represents a potential conflict of interest, it may be made available to reviewers and may be published at the Editor's discretion; authors will be informed of the decision before publication.

Sources of outside support for research, including funding, equipment, and drugs, must be named in the cover letter. The role(s) of the funding organization, if any, in the collection of data, its analysis and interpretation, and in the right to approve or disapprove publication of the finished manuscript must be described in the Methods section of the text.

Informed Consent: The Journal adheres to the principles set forth in the Helsinki Declaration (www.wma.net/e/policy/b3.htm) and holds that all reported research conducted with human participants should be conducted in accordance with such principles. Reports describing data obtained from research conducted in human participants must contain a statement in the Methods section indicating approval by the institutional review board and affirmation that informed consent was obtained from each participant. If patients are identifiable from illustrations, photographs, case reports, or other study data, release forms (or copies of the figures with the appropriate release statement) giving permission for publication must be submitted with the manuscript.

Humane Animal Care: All papers reporting experiments using animals must include a statement in the Methods section giving assurance that all animals have received humane care in compliance with the "Guide for the Care and Use of Laboratory Animals" (www.nap.edu/catalog/5140.html). Papers submitted from outside the United States must be in compliance with the guidelines established by their country's government or those of the National Institutes of Health and must include a statement to that effect in the Methods section.

Consultant Statistician and Statistical Methods: All manuscripts with statistical analysis are required to undergo biostatistical review to ensure adequate and appropriate study design, analysis, interpretation, and reporting. The Journal requires that a biostatistician review these manuscripts prior to submission. The most appropriate way to involve a biostatistician is as a consultant or coauthor from the investigators' home institution or collaborative group. The individual must complete and sign the Statistical Collaboration/Review Release Statement, available online (www. ctsnet.org/journals/jtcsstatisticalmethods.pdf) and published twice yearly (January and July issues) in the Journal. Manuscripts may undergo further biostatistical review by the Journal after submission. Additional information on statistical methods can be found in "Uniform Requirements for Manuscripts Submitted to Biomedical Journals" (www.icmje.org).

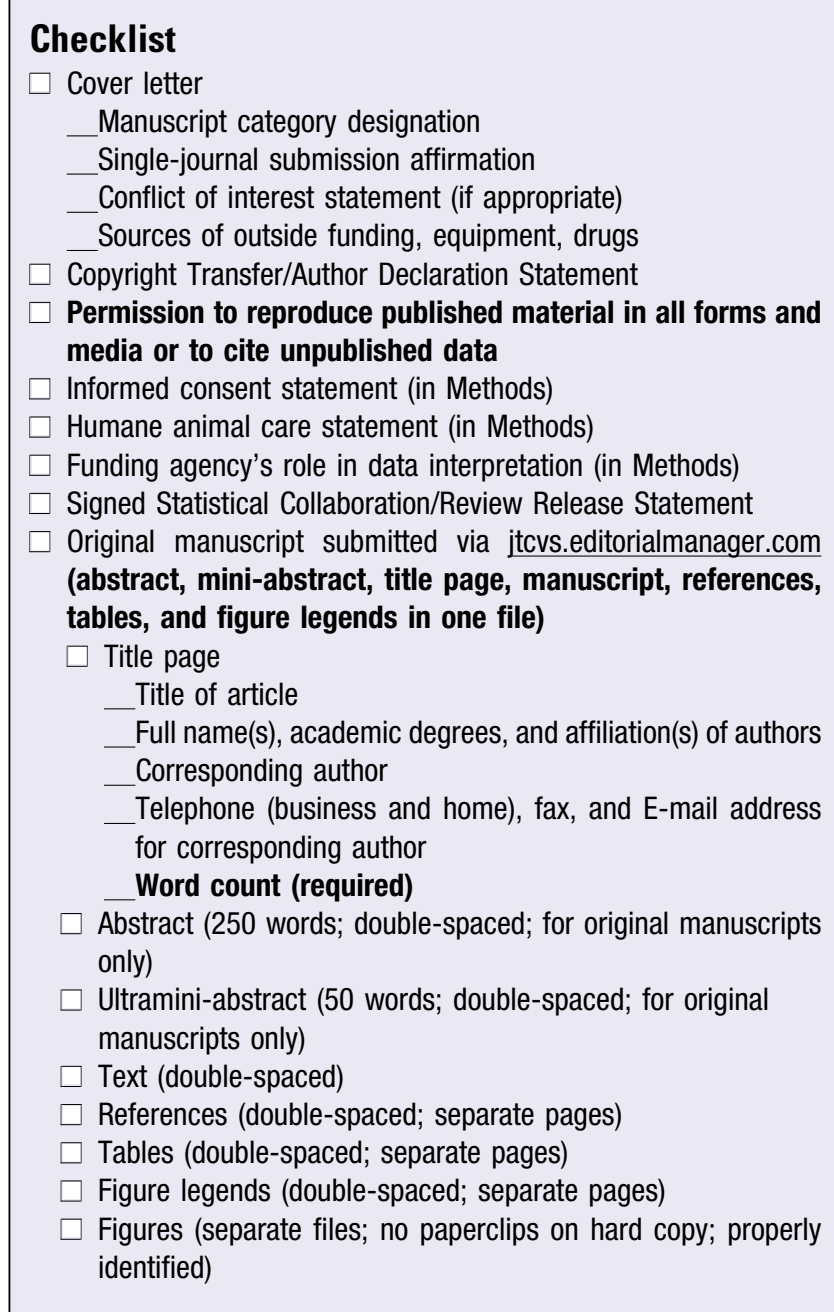

Copyright Statement: According to the Copyright Act of 1976, all manuscripts must be accompanied by the Copyright Transfer and Author Declaration Statement form that is available online at www.ctsnet.org/journals/jtcscopyrightform.pdf and in each issue of the Journal following the Information for Authors section. All authors must sign this statement.

Dates of Receipt and Acceptance: The "received for publication" date is the date when the editorial office receives the complete manuscript via Editorial Manager. The "accepted for publication" date is the date when the manuscript has met all of the requirements of the editorial office regarding provision of the final revised manuscript on disk and all camera-ready figures.

\section{Article Preparation}

Manuscripts must be written so that a reasonably well-informed member of the thoracic surgical community can understand them. The primary goal of the Journal is the dissemination of information and education. Arcane content must be explained and considered understandable by the editorial staff. Articles are chosen based on their probability of achieving this goal. Authors are 
encouraged to follow the principles of clear scientific writing, such as those described by Gopen and Swan. ${ }^{1}$

All manuscripts must adhere to the length requirements outlined below.

NOTE: To allow all manuscripts to be judged fairly, manuscripts exceeding length limitations will be returned for shortening prior to review.

Original Research Article: The Journal publishes original research in surgery and translational physiology as it relates to acquired and congenital cardiovascular disease, cardiothoracic transplantation, and general thoracic surgery. Meritorious work from closely related specialties, such as anesthesiology, molecular biology, pathology, pulmonary medicine, cardiology, and perfusion, will receive appropriate consideration if the linkage to our specialty is clear.

Original research articles are grouped in the Journal according to one of the following categories: Surgery for Acquired Cardiovascular Disease; Surgery for Congenital Heart Disease; General Thoracic Surgery; Cardiopulmonary Support and Physiology; Evolving Technology; Cardiothoracic Transplantation. Authors are asked to self-categorize their articles during the submission process.

Length Requirements: Original research articles may not exceed 6 printed pages, including title and abstract. Additional content may be designated as online only, for example, appendices, tables, figures, video clips. The following approximations between printed pages and typed pages are offered to help you calculate the number of printed pages your typed manuscript will translate to:

- 0.5 printed page $=$ article title and 250 -word structured abstract

- 1 printed page $=3.7$ typed $8.5 \times 11$ pages, double-spaced (approximately 250 typed words per page)

- 0.67 printed page $=30$ typed references (maximum allowed; double-spaced)

- 1 printed page $=3$ tables or figures with legends

NOTE: Word count must be included on title page of manuscript.

Clinical-Pathological Conference: This can be an important educational tool. Acceptance is based upon the learning opportunities presented by careful exposition of the case material, scholarly use of the literature to present treatment options, and discussion of patient outcome in the context of evidence-based medicine as the determinant for management and diagnosis-based issues. Unusual or rare entities are better treated as brief communications. Content should include appropriate illustrative material and may be supplemented by additional illustrative content that will appear in electronic form and may include digitized videos and illustrations.

\section{Length Requirements: Same as for original manuscripts.}

Brief Communication: The Editors are interested in brief clinical contributions containing substantive information concerning clinical studies or a pertinent observation. These submissions will be chosen on their discussion and educational value and on their scholarly use of the literature. Authors are given the choice of (1) rapid publication via online-only publishing or (2) normal publication schedule via print and online.

Length Requirements: Brief communications should contain no more than 750 words and 2 tables or figures and no more than 5 references. They do not need a structured abstract or an ultramini-abstract.

Letters to the Editor: Readers are encouraged to submit commentary on articles published in the Journal. Letters should be of broad interest to readers and not designed to "split hairs." Conflicting opinions on broad issues are particularly welcome when documentation is possible. Letters may be published together with a reply from the original author. If the original author does not respond, a notation indicating "Response declined" will be published. Substantive Letters to the Editor are indexed in Index Medicus.

Length Requirements: Letters to the Editor should not exceed 500 words, 1 figure or table, 3 authors, and 5 references.

\section{Manuscript Preparation}

Title Page: Provide a concise, informative title, with no unnecessary words (eg, Studies in . . .). List all authors' academic degrees and affiliations. Include all sources of funding for the work and complete name, address, business and home telephone and fax numbers, and E-mail address of the corresponding author. Article word count on title page is required.

Abstract: The structured abstract (required for original manuscripts only) should be limited to 250 words, should not include acronyms or abbreviations, and should contain the following sections:

1. Objective(s): describe the hypothesis or the purpose of the study

2. Methods: identify the study design and statistical methods used

3. Results: describe the outcome of the study and the statistical significance, if appropriate

4. Conclusions: state the significance of the results

Please provide a word count.

Ultramini-Abstract (required for original manuscripts only): Provide 1 to 3 sentences of no more than 50 words total, containing the essence of the manuscript, to include immediately beneath the title of the paper in the table of contents.

Units of Measurement: Report measurements of length, height, weight, and volume in metric units (meter, kilogram, or liter) or their decimal multiples. Give temperatures in degrees Celsius and blood pressures in millimeters of mercury. All hematologic and clinical chemistry measurements should be reported in the metric system in terms of the International System of Units (SI). The authors should also add alternate or non-SI units before publication. See www.acponline.org/journals/resource/unifreqr.htm for more details.

Abbreviations: Except for units of measurements, abbreviations are discouraged. Abbreviations that are used should be defined at 
first mention. Internationally accepted abbreviations such as AIDS, DNA, SD, and TNM need not be defined. For commonly accepted abbreviations, word usage, symbols, and so forth, please consult Scientific Style and Format ${ }^{2}$ and the American Medical Association Manual of Style. ${ }^{3}$

References: Limit references to directly pertinent published works or papers that have been accepted for publication. Unpublished data and personal communications should be cited only in the text, not as a numbered reference. Authors wishing to cite unpublished material must have a letter of permission from the originator of the communication to do so. This letter should be submitted with the manuscript. Number references serially in the text and list them, on a separate page, double-spaced, at the end of the paper in numerical order.

Reference format should conform to that set forth in "Uniform Requirements for Manuscripts Submitted to Biomedical Journals" (www.acponline.org/journals/resource/unifreqr.htm) and journal abbreviations should conform to the style used in the Cumulated Index Medicus. The style of citation should be as follows:

Journals: authors' last names and initials; title of article; journal name; date; volume number, and inclusive pages (list all authors when six or fewer; when seven or more, list six and add $e t$ al):

Graeber GM, Gupta NC, Murray GF. Positron emission tomographic imaging with fluorodeoxyglucose is efficacious in evaluating malignant pulmonary disease. $J$ Thorac Cardiovasc Surg. 1999;117:719-27.

Lytle BW, Blackstone EH, Loop FD, Houghtaling PL, Arnold JH, Akhrass R, et al. Two internal thoracic artery grafts are better than one. J Thorac Cardiovasc Surg. 1999;117:855-72.

Books: authors' last names and initials; chapter title, editor's name, book title, edition, city, publisher, date, and pages:

Mollnes TE. Analysis of in vivo complement activation: In: Herzenberg LA, Weir DM, Herzenberg LA, Blackwell C, editors. Weir's handbook of experimental immunology. Volume 78, 5th ed. Boston: Blackwell Science; 1997 , p. 78.1-78.8.

Figures: For help with preparing electronic artwork for both on-screen review and eventual publication, see the information page created by Elsevier Inc. (http://authors.elsevier.com/artwork).

Figures must be of professional quality. When possible, please use first-generation artwork. Number figures in the order of their appearance in the text.

The Journal will reproduce free of cost to the author a reasonable number of black and white illustrations and a limited number of color illustrations if appropriate.

Graph Creation: See http://jtcs.ctsnetjournals.org/misc/ifora.shtml for more details.

\section{Efficient Use of Space:}

- Eliminate blank spaces that contain no information (eg, delete points on the $\mathrm{x}$ and $\mathrm{y}$ axes that do not contain data)

- Do not border a figure or a key with a box
- If they fit, place keys that apply to the figure within the figure itself (without a box); if the key does not fit in the figure, place it at the end of the legend

- Create figures in scale with each other to the extent possible

\section{Effective Formatting:}

- Do not use background horizontal lines

- Avoid 3-dimensional art

- Make sure both axes are labeled

- Most figures will be one column wide. Ensure that all data and type within a figure are sized according to these guidelines to the extent possible

- Use uppercase and lowercase type: It is much easier to read than all capital letters

- Use a consistent type face and size (Helvetica or Universe, 11 or 12 points) throughout (avoid sans serif types such as Courier)

- Use a bold typeface for emphasis; it is much more readable than italics or underlining

- Avoid gray shading; it does not reproduce well

- Make lines thick enough to ensure adequate reproduction (extremely thin lines do not reproduce well).

\section{General Instructions:}

- For figures submitted in electronic format, all images should be at least 5 inches wide. Images should be provided in EPS or TIF format (for those mailed to the Editorial Office, on Zip Disk, CD, floppy, Jaz, or 3.5 MO)

- Graphics software such as Photoshop and Illustrator, not presentation software such as PowerPoint, CorelDraw, or Harvard Graphics, should be used to create art

- Color images need to be CMYK, at least $300 \mathrm{dpi}$, with a digital color proof, not a color laser print or color photocopy

- Gray scale images should be at least 300 dpi accompanied by a proof

- Line art (black and white or color) and combinations of gray scale and line art should be at least 1200 dpi and accompanied by a proof

- For best reproduction, screening, shading, and lettering on a dark background should be avoided

Tables: Tables should be self-explanatory and should supplement, not duplicate, the text. Each table should be on a separate page. Provide a brief title for each. Abbreviations used in the table should be defined at the bottom of the table.

Cover Letter: Include with the manuscript a cover letter that provides (1) the category of manuscript (eg, original research, Brief Communication, Letter to the Editor); (2) statement that the material has not been previously published or submitted elsewhere for publication; (3) information about any personal conflicts of interest of any of the authors; and (4) names of sources of outside support for research, including funding, equipment, and drugs (see Conflict of Interest above). You may also submit the name of one reviewer of your choice. You should include that individual's mailing address, telephone number, fax number, and E-mail address. You should know that the reviewer will be asked to review the manuscript at your request but will also be informed that his or 
her identity will be kept confidential. Assigning suggested reviewers is done at the discretion of the editor handling your manuscript.

\section{Manuscript Submission}

Electronic Submission: All manuscripts must be submitted via Editorial Manager (http://jtcvs.editorialmanager.com) and should include the following items:

- Cover letter

- Abstract and mini-abstract (original manuscripts only)

- Title page with word count

- Manuscript (using word processor file)

- Tables

NOTE: Please include abstract, mini-abstract, title page, manuscript, tables, and figure legends in one file.

- Figures (attach as separate files)

The following items that accompany the manuscript may be scanned and submitted electronically or submitted by mail if scanning is not an option:

- Copyright Transfer/Author Declaration Statement

- Permission to reproduce published material (if applicable)

- Statistical Collaboration/Review Statement (if applicable)

\section{General Guidelines:}

NOTE: It is the author's responsibility to ensure that each submitted version of the manuscript is the correct version and that each version is clearly marked.

- Format all text elements as double spaced for easier reading.

- Insert page breaks between the title page, abstract, ultraminiabstract, and first page of text.

- Begin text, acknowledgements, references, and figure legends, respectively, on separate pages.

- Begin each table on a separate page.

- Write text in clear and concise language, using accepted standards of English style and usage. Define unfamiliar or new terms when first used and avoid use of jargon, clichés, and laboratory slang.

- On the title page, include the title of the article and the author(s) name(s), degree(s), and institutional affiliation(s) as well as the name, telephone number, fax number, and E-mail address of the corresponding author. Where necessary, identify each author's affiliation by superscript numbers matched to the appro- priate institutions. Also include word count of the manuscript (required).

NOTE: To view your manuscript in PDF format on Editorial Manager, you must have Adobe Acrobat Reader 7.0 installed on your computer. (Download the free Adobe Acrobat Reader.)

\section{Manuscript Revision:}

- Revised manuscripts must be submitted in three parts as wordprocessing files (pdf files are not acceptable): (1) cover letter with responses to reviewers' comments; (2) revised, marked manuscript showing additions and deletions; (3) revised, unmarked manuscript.

- The organization of a revised manuscript is very important in the review process. Most manuscripts submitted to the Journal are revised at least once. Please structure your response as follows:

- The reviewer's comment to which you are responding

- Your response

- How that response is manifest in the revised manuscript

- A response to each and every reviewer comment

\section{Manuscript Processing}

Acknowledgment of Receipt: Each submission is assigned a unique number and acknowledged by E-mail. The editorial office considers the manuscript number a confidential communication, which should be given only to other authors of the paper. The editorial office staff releases information about manuscripts only to authors who provide the manuscript number. Information about a specific manuscript can be obtained via Editorial Manager only by the corresponding author or his designated representative who has access to his personal username and password.

\section{Print References}

1. Gopen GD, Swan JA. The science of scientific writing. Am Sci. 1990;78:550-8.

2. Scientific Style and Format: The CBE Manual for Authors, Editors, and Publishers, 6th ed. New York: Cambridge University Press; 1994.

3. Iverson, Cheryl, et al, editors. American Medical Association Manual of Style, 9th ed. Baltimore: Williams and Wilkins, 1998. 